\title{
Penetapan Kadar Asam Salisilat pada Krim Anti Jerawat yang Beredar di Kota Bandung dengan Metode Spektrotometri Ultra Violet
}

\section{Determination of Salicylic Acid in Anti Acne Cream which Circulated Around Bandung City Using Ultra Violet Spectrophotometry Method}

\author{
Ginayati Hadisoebroto ${ }^{1, *}$ dan Senadi Budiman ${ }^{2}$ \\ ${ }^{1}$ Program Studi Farmasi Fakultas Matematika dan Ilmu Pengetahuan Alam, Universitas Al-Ghifari, Bandung \\ ${ }^{2}$ Program Studi Kimia, Fakultas Sains dan Informatika, Universitas Jenderal Achmad Yani, Cimahi \\ *E-mail : gina.hs11@gmail.com
}

DOI: https://doi.org/10.26874/jkk.v2i1.20

Received:, Revised:, Accepted:, Online:

\begin{abstract}
Abstrak
Asam salisilat merupakan zat anti jerawat sekaligus keratolitik yang lazim diberikan secara topikal. Tujuan penelitian ini adalah untuk mengetahui kadar asam salisilat pada krim anti jerawat yang beredar di pasar tradisional, swalayan, dan skin care Kota Bandung, dan membandingkan kadar asam salisilat dalam sampel dengan batas kandungan asam salisilat maksimum yang ditentukan oleh Balai Besar Pengawas Obat dan Makanan (BPOM) yaitu < 2\%. Analisis kualitatif menggunakan metode kromatografi lapis tipis (KLT) dengan fase gerak toluen : asam asetat (4:1) dan uji warna menggunakan pereaksi $\mathrm{FeCl}_{3}$. Sedangkan analisis kuantitatif asam salisilat pada krim anti jerawat menggunakan pelarut etanol dan diukur dengan spektrofotometer UV. Validasi metode dilakukan untuk membuktikan bahwa metode yang digunakan telah memenuhi persyaratan. Kadar asam salisilat dalam sampel $\mathrm{G}$ adalah 2,33\%, C 1,54 \%, B 0,71\%, R 0,85\%, dan I 0,82\%. Sampel C, B , R dan I memenuhi persyaratan yang telah ditetapkan oleh Balai Besar Pengawas Obat dan Makanan (BPOM) yaitu tidak lebih dari 2\%, sedangkan sampel $\mathrm{G}$ tidak memenuhi persyaratan yang telah ditetapkan karena kadarnya lebih dari $2 \%$.
\end{abstract}

Kata kunci: asam salisilat, kromatografi lapis tipis, spektrofotometer ultraviolet

\begin{abstract}
Salicylic acid is an anti-acne as well as keratolytic which is commonly given topically. The purpose of this study was to determine the levels of salicylic acid in anti-acne creams circulating in traditional markets, supermarkets, and skin care in Bandung, and to compare the levels of salicylic acid in samples with the maximum salicylic acid content limit determined by the Center for Drug and Food Control (BPOM). Qualitative analysis using the thin layer chromatography (TLC) method with the toluene mobile phase: acetic acid (4: 1) and color test using $\mathrm{FeCl}_{3}$ reagent. While the quantitative analysis of salicylic acid in anti-acne cream using ethanol solvent and measured by a UV spectrophotometer. Method validation to prove that the method used has reached the requirement. Salicylic acid levels in sample G were $2.33 \%, C 1.54 \%, B 0.71 \%, R 0.85 \%$, and I 0.82\%. Samples C, B, R and standard sample set by BPOM which is no more than $2 \%$. Sample G does not unqualified because the level is more than $2 \%$.
\end{abstract}

Keywords: salicylic acid, thin layer chromatography, UV spectrophotomety 


\section{Pendahuluan}

Kosmetika merupakan campuran bahan obat untuk digosokkan, dilekatkan, dituang-kan, dipercikan, atau disemprotkan, dima-sukkan ke dalam, bagian badan manusia dengan maksud untuk membersihkan, memelihara, menambah daya, dan tidak termasuk golongan obat. Kosmetika dapat mempengaruhi struktur dan faal kulit. Bahan tersebut misalnya anti jerawat (sulfur, resorsin), anti jasad renik (heksaklorofen), anti pengeluaran keringat (aluminium klorida), plasenta, atau hormon (estrogen) [1].

Campuran bahan kosmetika yang berlebihan merugikan jika, pengolahan yang kurang baik, penggunaan bahan yang tidak tepat dan penyimpanan yang tidak higienis. Reaksi kulit terhadap kosmetik terjadi jika kita peka terhadap salah satu bahan baku kosmetik. Reaksi kulit tersebut akan menimbulkan kelainan. Salah satu kelainan pada kulit yang terjadi adalah iritasi kulit. Kulit akan mengalami iritasi, biasanya setelah pemakaian kosmetik. Kelainan yang terjadi berupa kulit kemerahan, biasanya terasa panas, perih, dan kadang-kadang permukannya berair [2].

Pemilihan sediaan yang tepat memiliki peran penting terhadap efektivitas terapi. Terapi jerawat, krim merupakan sediaan yang tepat karena lebih mudah dioleskan dan tidak berlemak layaknya sediaan salep. Bahan pembawa pada formulasi suatu sediaan akan mempengaruhi jumlah dan kecepatan difusi zat aktif hingga dapat diabsorpsi memberikan efek [3].

Asam salisilat merupakan zat anti jerawat sekaligus keratolitik yang lazim diberikan secara topikal adapun struktur molekulnya pada gambar 1. Bekerjanya dengan memecah struktur desmosom pada korneosit dengan cara menghilangkan ikatan kovalen lipid intraselular disekitar keratinosit. Pemakaian asam salisilat pada konsentrasi tinggi juga sering mengakibatkan iritasi lokal dan peradangan akut.

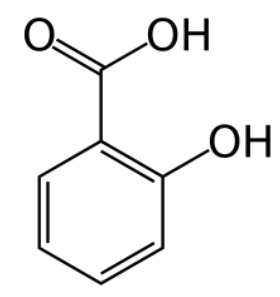

Gambar 1. Struktur molekul asam salisilat

Untuk mengurangi absorpsinya pada penggunaan topikal maka asam salisilat tidak digunakan dalam penggunaan jangka lama dalam konsentrasi tinggi, pada daerah yang luas pada kulit dan pada kulit rusak. Kadar Asam salisilat yang boleh digunakan tidak lebih dari $2 \%$ [4].

Berdasarkan latar belakang yang telah diuraikan, dapat di identifikasi beberapa masalah yaitu Berapakah kadar asam salisilat yang terdapat dalam sediaan kosmetika krim anti jerawat yang beredar di pasar tradisional, swalayan dan Skin Care di Kota Bandung. Apakah kadar asam salisilat dalam sampel kosmetika krim anti jerawat memenuhi persyaratan yang ditetapkan oleh Balai Besar Pengawas Obat dan Makanan (BPOM). Penelitian ini bertujuan untuk mengetahui kadar asam salisilat pada krim anti jerawat yang beredar di pasar tradisional, swalayan dan Skin Care Kota Bandung [5].

Penelitian ini diharapkan dapat membuktikan keamanan kosmetika krim anti jerawat yang beredar di Bandung lolos uji keamanan dan menambah pengetahuan tentang identifikasi asam salisilat dalam krim anti jerawat.

\section{Metode Penelitian}

\subsection{Pengambilan Sampel}

Pengambilan sampel secara acak didasarkan pada produk krim anti jerawat yang beredar di pasar tradisional, swalayan dan Skin Care di Kota Bandung, yaitu Pasar Ujung Berung, Pasar Andir, Pasar Sukajadi, Yogya Grand Kepatihan, Skin Care X, Skin Care Y, dan Beauty Seeker.

\subsection{Larutan Uji Sampel Krim}

Sampel yang mengandung asam salisilat ditimbang 1,00 g, dimasukkan ke dalam gelas kimia, dlarutkan dalam $10 \mathrm{~mL}$ etanol sambil dipanaskan diatas penangas air, diaduk hingga homogen, tutup dengan alumunium foil. Dinginkan dalam es selama 15 menit dan saring melalui kertas saring. Filtrat ditampung dalam labu ukur, Tambahkan etanol hingga tanda batas dan homogenkan [5].

\subsection{Larutan Standar Asam Salisilat}

Sebanyak $50 \mathrm{mg}$ standar asam salisilat ditimbang, dimasukkan ke dalam labu ukur. Dilarutkan dalam etanol sampai tanda batas sehingga diperoleh larutan standar asam salisilat 1000 ppm. 


\subsection{Analisis Kualitatif Asam Salisilat Uji Warna}

Sampel yang telah dilarutkan diteteskan sebanyak 2 tetes pada plat tetes, ditambahkan pereaksi $\mathrm{FeCl}_{3}$, diamati perubahan yang terjadi. Reaksi positif memberikan warna ungu.

\section{Kromatografi Lapis Tipis}

Dimasukan toluen - asam asetat glasial $(4: 1)$ ke dalam chamber, tutup dengan plat kaca, di jenuhkan selama 45 menit. Identifikasi Sampel dengan KLT. Lempeng KLT di panaskan di dalam oven pada suhu $105^{\circ} \mathrm{C}$ selama 30 menit, di buat batas penotolan dan batas elusi $10 \mathrm{~cm}$. Larutan uji ditotolkan secara terpisah dengan menggunakan pipa kapiler dengan jarak 1,5 cm dari bagian bawah lempeng. Lempeng KLT yang telah mengandung cuplikan dimasukan kedalam bejana KLT yang terlebih dahulu dijenuhkan dengan fase gerak berupa toluene dan asam asetat (4:1). Dibiarkan fasa bergerak naik sampai mendekati batas elusi. Lempeng KLT diangkat dan dibiarkan kering diudara. Diamati di bawah sinar $\mathrm{UV}_{254}$ berfluoresensi memberikan bercak gelap [5].

\subsection{Analisis Kuantitatif Asam Salisilat Penentuan Linearitas}

Dipipet larutan asam salisilat $100 \mathrm{ppm}$ ke dalam labu ukur $10 \mathrm{~mL}$ berturut-turut 0,$3 ; 0,6 ; 0,9$; 1,$2 ; 1,5$ dan $1,8 \mathrm{~mL}(3 ; 6 ; 9 ; 12 ; 15$ dan 18 ppm). Ditambahkan etanol sampai tanda batas ke dalam masing-masing labu ukur tersebut. Dikocok hingga homogen, diukur serapannya pada $\lambda_{\text {maks }}$ yang diperoleh menggunakan larutan blanko.

\section{Penentuan Akurasi}

Sebanyak 0,3, 0,9, dan 1,5 mL standar 100 ppm, ditambahkan etanol pada labu ukur hingga tanda batas. Absorbansi diukur pada $\lambda_{\text {maks. }}$ Absorbansi dimasukkan ke dalam persamaan regresi dari kurva kalibrasi. Konsentrasi perolehan kembali (PK) dibandingkan dengan nilai yang seharusnya [6].

Keterangan

$$
\operatorname{PK}(\%)=\frac{a}{b} \times 100 \%
$$

$\mathrm{a}=$ konsentrasi perolehan kembali

$\mathrm{b}=$ konsentrasi standar

\section{$\underline{\text { Penentuan Presisi }}$}

Sebanyak $1,5 \mathrm{~mL}$ standar $100 \mathrm{ppm}$ ditambah etanol pada labu ukur (15 ppm), hingga tanda batas. Absorbansi diukur pada $\lambda_{\text {maks. }}$ Larutan ini dibuat sebanyak enam kali ulangan. Penentuan presisi dinyatakan dengan koefisien variasi atau KV (\%) (Gandjar dan Rohman, 2013).

Keterangan:

$$
\% \mathrm{KV}=\frac{\mathrm{S}}{\mathrm{X}}
$$

$\mathrm{KV}=$ Koefisien variasi

$\mathrm{S}=$ Standar deviasi

$\mathrm{x}=$ Rata-rata

Penentuan Batas Deteksi (BD) dan Batas $\underline{\text { Kuantitasi (BK) }}$

$$
\begin{aligned}
& \mathrm{BD}=\frac{3 \mathrm{SD}}{\text { slope }} \\
& \mathrm{BK}=\frac{10 \mathrm{SD}}{\text { slope }}
\end{aligned}
$$

\section{$\underline{\text { Penetapan Kadar Asam Salisilat }}$}

Dipipet sebanyak 1,00 $\mathrm{mL}$ larutan uji dimasukkan ke dalam labu ukur. Tambahkan etanol sampai tanda batas dan homogenkan. Absorbansi diukur pada $\lambda_{\text {maks }}(235,6 \mathrm{~nm})$.

\section{Hasil dan Diskusi}

\subsection{Pengambilan Sampel}

Pengambilan sampel secara acak pada produk krim anti jerawat yang beredar di Bandung, yaitu Pasar Ujung Berung, Pasar Andir, Pasar Sukajadi, Yogya Grand Kepatihan, Skin Care X, Skin Care Y, dan Beauty Seeker. Tujuh sampel digunakan dengan pengkodean.

\subsection{Identifikasi dengan Uji Warna}

Asam salisilat mengandung fenol maka reaksinya dengan $\mathrm{FeCl}_{3}$ akan menghasilkan warna ungu. Reaksi positif memberikan perubahan warna ungu setelah ditetesi $\mathrm{FeCl}_{3}$. Hasil uji warna disajikan dalam Tabel 1. 
Tabel 1. Identifikasi Uji Warna Sampel Krim

\begin{tabular}{cc}
\hline Sampel & Reaksi \\
\hline G & + \\
C & + \\
B & + \\
R & + \\
I & + \\
Skin Care X & - \\
Skin Care Y & - \\
\hline Keterangan : Terjadi reaksi (+) \\
\multicolumn{2}{r}{ Tidak terjaid reaksi (-) }
\end{tabular}

Pada sampel Skin Care X dan Y ketika ditambahkan dengan $\mathrm{FeCl}_{3}$ tidak terjadi peubahan warna. Hal ini menunjukkan sampel tidak mengandung asam salisilat.

\subsection{Identifikasi dengan Uji Warna}

Kromatografi Lapis Tipis (KLT) merupakan cara pemisahan campuran senyawa menjadi senyawa murninya. Identifikasi pemisahan komponen dapat dilakukan dengan pereaksi warna, fluore-sensi, atau dengan radiasi menggunakan sinar ultra violet. Hasil identifikasi sampel dengan KLT disajikan dalam Tabel 2.

Tabel 2. Identifikasi Sampel dengan KLT

\begin{tabular}{ccc}
\hline Sampel & $\begin{array}{c}\text { Tinggi Bercak } \\
(\mathbf{c m})\end{array}$ & $\begin{array}{c}\mathbf{R f} \\
(\mathbf{c m})\end{array}$ \\
\hline Asam salisilat & 3,20 & 0,47 \\
G & 3,70 & 0,52 \\
C & 3,50 & 0,50 \\
B & 3,10 & 0,44 \\
R & 3,50 & 0,50 \\
I & 3,40 & 0,48 \\
Skin Care X & 5,10 & 0,72 \\
Skin Care Y & 4,41 & 0.63 \\
\hline
\end{tabular}

Dari hasil analisis diperoleh bahwa nilai $\mathrm{Rf}$ sampel G, C, B, R dan I memiliki nilai Rf saling berdekatan dengan standar asam salisilat, sedangkan sampel skin care $\mathrm{X}$ dan $\mathrm{Y}$ memiliki nilai $\mathrm{Rf}$ yang tidak saling berdekatan. Dua senyawa dikatakan identik jika mempunyai nilai Rf yang sama diukur pada kondisi KLT yang sama. Hal ini menunjukkan bahwa kedua sampel tidak mengandung asam salisilat.

\subsection{Analisis kadar asam salisilat \\ Metode Validasi}

Metode validasi analisis merupakan suatu tindakan penilaian terhadap parameter tertentu, berdasarkan percobaan laborato-rium ,untuk membuktikan bahwa parameter tersebut memenuhi persyaratan untuk penggunaannya [7]. Hasil Penentuan Linieritas

Linieritas merupakan ukuran yang menunjukkan tingkat kesesuaian antara kadar analit dengan respon detektor (Gandjar dan Rohman, 2007). Hasil pengukuran linieritas yang diperoleh tercantum dalam tabel 4.3. Dari data tersebut dapat dibuat grafik konsentrasi terhadap absorbansi disajikan pada Gambar 3.

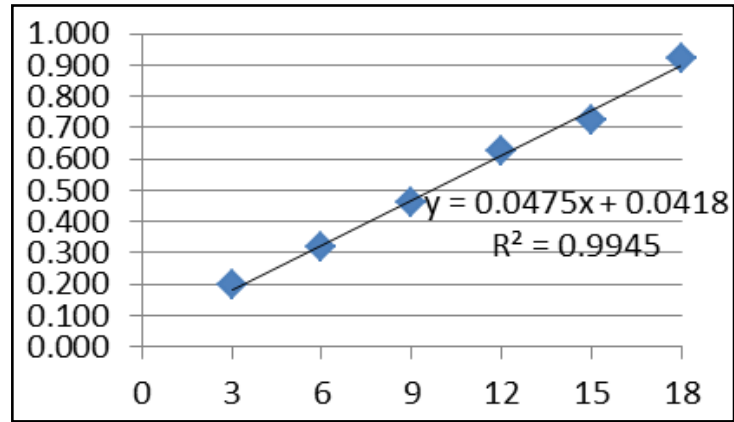

Gambar 3. Kurva Linieritas Konsentrasi terhadap Absorbansi

\begin{tabular}{ccccc}
\hline $\begin{array}{c}\text { C } \\
\text { (ppm) }\end{array}$ & A 1 & A 2 & A 3 & Rata-rata \\
\hline 3 & 0,195 & 0,198 & 0,199 & 0,197 \\
6 & 0,309 & 0,322 & 0,324 & 0,318 \\
9 & 0,489 & 0,454 & 0,443 & 0,462 \\
12 & 0,619 & 0,623 & 0,631 & 0,624 \\
15 & 0,712 & 0,725 & 0,732 & 0,723 \\
18 & 0,917 & 0,913 & 0,931 & 0,920 \\
\hline
\end{tabular}

Tabel 3. Pengukuran Linieritas Asam Salisilat

Persamaan garis linier berupa $\mathrm{y}=$ $0,0475 \mathrm{x}+0,0418$, dengan nilai koefisien korelasi $r^{2}=0,994$. Hal ini menunjukkan bahwa kurva yang diperoleh adalah linier, karena adanya kesesuaian atau korelasi yang baik antara kadar analit dan respon detector. Hal ini sesuai dengan syarat parameter linieritas yaitu lebih besar dari 0,990 (ICH, 1994).

\section{Hasil Penentuan Akurasi}

Akurasi merupakan kedekatan hasil uji antara hasil yang diperoleh dengan nilai sebenarnya (true value) atau dengan nilai referensinya [8]. Penilaian akurasi berdasarkan perolehan kembali (recovery). Nilai recovery dihitung dari kadar 
yang terukur atau kadar hasil dibandingkan dengan kadar yang sebenarnya dikalikan $100 \%$. Akurasi dikatakan baik jika recovery berada dalam rentang 90-110\%. Hasil pengukuran akurasi yang diperoleh tercantum dalam tabel 4 .

\begin{tabular}{cc}
\hline $\begin{array}{c}\text { Konsentrasi } \\
(\mathbf{p p m})\end{array}$ & $\begin{array}{c}\text { Perolehan Kembali } \\
(\boldsymbol{\%})\end{array}$ \\
\hline 3 & 106.807 \\
3 & 105.404 \\
3 & 104.702 \\
9 & 93.614 \\
9 & 94.784 \\
9 & 95.018 \\
15 & 99.537 \\
15 & 99.677 \\
15 & 99.958 \\
\hline
\end{tabular}

Tabel 4. Hasil Pengukuran Parameter Akurasi

Nilai \%PK sebesar 93,61-106,81\%, telah memenuhi batas penerimaan \%PK, yaitu 90$110 \%$. Hal ini menunjukkan bahwa metode yang digunakan telah memenuhi syarat akurasi dengan memiliki nilai ketepatan dan ketelitian yang baik.

\section{Hasil Penentuan Presisi}

Presisi merupakan kedekatan hasil uji dengan cara memperoleh pengukuran dari berbagai contoh yang homogen dalam kondisi yang normal [8]. Presisi diukur sebagai simpangan baku atau simpangan baku relatif (koefisien variasi). Hasil pengukuran presisi yang diperoleh tercantum dalam tabel 5.

KV telah memenuhi syarat nilai keseksamaan yang diterima yaitu kurang dari $2 \%$ sehingga metode tersebut memiliki nilai keterulangan yang baik [9].

\section{Batas Deteksi dan Batas Kuantitasi}

Batas deteksi merupakan jumlah terkecil analit dalam sampel yang dapat dideteksi yang masih memberikan respon yang significant dibandingkan dengan blanko. Sedangkan batas kuantisasi merupakan jumlah terkecil analit dalam sampel yang masih memenuhi criteria cermat dan seksama dan dapat dikuantifikasi dengan akurasi dan presisi yang baik [10]. Hasil perhitungan didapatkan batas deteksi sebesar 0,632 dan batas kuantitasi sebesar 2,104.

\section{Penetapan Kadar Asam Salisiliat}

Penetapan kadar asam salisilat dalam krim anti jerawat yang beredar di pasar tradisional, swalayan dan skin care di Kota Bandung dilakukan dengan menggunakan spektrofotometer ultraviolet yang telah dilakukan optimasi dan validasi. Kadar asam salisilat pada krim anti jerawat disajikan pada Tabel 6 .

Tabel 5. Pengukuran Parameter Presisi

\begin{tabular}{cc}
\hline $\begin{array}{c}\text { Konsentrasi } \\
\text { ( ppm })\end{array}$ & Kadar ( ppm ) \\
\hline 15 & 14,909 \\
15 & 14,931 \\
15 & 14,952 \\
15 & 14,931 \\
15 & 14,994 \\
15 & 14,973 \\
Rata-Rata & 14,948 \\
SD & 0,031 \\
KV & 0,207 \\
\hline
\end{tabular}

Tabel 6 Kadar asam salisilat krim anti Jerawat

\begin{tabular}{ccc}
\hline Sampel & $\begin{array}{c}\text { Konsentrasi } \\
\text { Sampel }\end{array}$ & $\begin{array}{c}\text { Kadar Asam } \\
\text { Salisilat dalam } \\
\text { Sampel (\%) }\end{array}$ \\
\hline G & 9.302 & 2.325 \\
C & 6.173 & 1.543 \\
B & 3.197 & 0.799 \\
R & 3.387 & 0.846 \\
I & 3.260 & 0.815 \\
\hline
\end{tabular}

Kadar asam salisilat dalam krim anti jerawat yang beredar di pasar tradisional, swalayan dan Skin Care Kota Bandung berada pada rentang antara 0,799-2,325\%. Sampel C, B, R dan I memenuhi persyaratan yang telah ditetapkan oleh Balai Besar Pengawas Obat dan Makanan (BPOM) yaitu tidak lebih dari $2 \%$, sedangkan sampel $\mathrm{G}$ tidak memenuhi persyaratan yang telah ditetapkan karena kadarnya lebih dari $2 \%$.

\section{Kesimpulan}

Kadar asam salisilat dalam krim anti jerawat krim $\mathrm{G}$ adalah $2,33 \%$, C $1,54 \%$, B $0,71 \%$, R $0,85 \%$, dan I $0,82 \%$ sehingga krim $G$ tidak memenuhi persyaratan yang telah ditetapkan oleh BPOM karena kadarnya lebih dari $2 \%$.

\section{Daftar Pustaka}

[1] Wasitaatmadja SM. Penuntun Ilmu Kosmetik Medik. Jakarta: Universitas Indonesia; 1997. 3. 
[2] Dwikarya. Merawat Kulit dan Wajah. Jakarta: Kawan Pustaka; 2003. 2.

[3] Wyatt EL, Sutter SH, Drake L. Dermatological Pharmacology. In: The Pharmacological Basic of Therapeutic. New York: Mc Graw Hill; 2001.

[4] Katzung BG. Farmakologi Dasar dan Klinik. Edisi II. Jakarta: Salemba Medika; 2002. 671, 677-678.

[5] Badan POM RI. Peraturan Kepala Badan Pengawas Obat dan Makanan Republik Indonesia Tentang Metode Analisis Kosmetika. HK.03.1. 23.08.11. 07331 Indonesia; 2011.

[6] Gandjar GH, Rohman A. Kimia Farmasi Analisis. Yogyakarta: Pustaka Pelajar; 2012. 463-466.
[7] Tetrasari H. Validasi Metode Analisis. Jakarta: Pusat Pengkajian Obat dan Makanan BPOM; 2003.

[8] Chan CC, Lam H, Lee YC, Zhang XM. Analitical Method Validation and Instrument Performance Verification. New Jersey: John Wiley \& Sons, Inc.; 2004.

[9] Harmita H. Petunjuk Pelaksanaan Validasi Metode dan Cara Perhitungannya. Maj Ilmu Kefarmasian. $2004 . \quad 1(3): 117-35$. http://dx.doi.org/10.7454/psr.v1i3.3375

[10] ICH Harmonised Tripartite Guideline. Validation Of Analytical Procedures. Text and Methodology Q2 (RI). Int Conf Harmon. 1994. 2(1):6. 